Research Paper/

\title{
Title: Broad-scale evidence that pH influences the balance between microbial iron and sulfate reduction
}

Matthew F. Kirk

Corresponding author: Kansas State University, Department of Geology, 108 Thompson Hall, Manhattan, KS 66506, USA, (office) 785-532-2616, (fax) 785-532-5159, mfkirk@ksu.edu

Qusheng Jin

University of Oregon, Department of Geological Sciences, 1272 University of Oregon, Eugene, OR 97403, USA, qjin@uoregon.edu

Ben R. Haller

Kansas State University, Department of Geology, 108 Thompson Hall, Manhattan, KS 66506, USA, benh22@ksu.edu

Conflict of interest and financial disclosure: none

Key words: microbiology, water quality, groundwater, geochemistry, bioenergetics, environmental change, principal aquifer system

Article Impact Statement: Broad-scale trends in groundwater chemistry indicate a shifting balance between microbial iron and sulfate reduction with $\mathrm{pH}$

\begin{abstract}
Understanding basic controls on aquifer microbiology is essential to managing water resources and predicting impacts of future environmental change. Previous theoretical and laboratory studies indicate that $\mathrm{pH}$ can influence interactions between microorganisms that reduce ferric iron and sulfate. Here we test the environmental relevance of this relationship by examining broad-scale geochemical data from anoxic aquifers. We isolated data from the U.S. Geological Survey National Water Information System for 19 principal aquifer systems. We then removed samples with chemical compositions inconsistent with iron- and sulfate-reducing environments and evaluated the relationships between $\mathrm{pH}$ and other geochemical parameters
\end{abstract}


using Spearman's rho rank correlation tests. Overall, iron concentration and the iron-sulfide concentration ratio of groundwater share a statistically significant negative correlation with $\mathrm{pH}$ $(P<0.0001)$. These relationships indicate that the significance of iron reduction relative to sulfate reduction tends to increase with decreasing $\mathrm{pH}$. Moreover, thermodynamic calculations show that, as the $\mathrm{pH}$ of groundwater decreases, iron reduction becomes increasingly favorable relative to sulfate reduction. Hence, the relative significance of each microbial reaction may vary in response to thermodynamic controls on microbial activity. Our findings demonstrate that trends in groundwater geochemistry across different regional aquifer systems are consistent with $\mathrm{pH}$ as a control on interactions between microbial iron and sulfate reduction. Environmental changes that perturb groundwater $\mathrm{pH}$ can affect water quality by altering the balance between these microbial reactions.

\section{Introduction}

Environmental changes that threaten groundwater resources come from many possible sources, including leakage of waste materials from subsurface storage reservoirs, agricultural contamination, hydraulic fracturing, and climate change (Böhlke 2002; Green et al. 2011; Harvey et al. 2013; Warner et al. 2012). The impact of such changes on groundwater resources in part depends on the response of subsurface microbial communities to perturbed conditions. Microorganisms influence, and in return are influenced by, the chemical and physical properties of the subsurface (Chapelle 2001; Flynn et al. 2013; Gerlach and Cunningham 2010). Therefore, a clear understanding of environmental controls on microbial processes is vital to our ability to predict and manage consequences of environmental change. 
In this study, we consider $\mathrm{pH}$ as a control on the balance between microbial iron and sulfate reduction in aquifer systems. Microbial iron and sulfate reduction are the two most common redox processes in anoxic aquifers (McMahon and Chapelle 2008). During iron reduction, microbes use ferric iron, most commonly in oxides and oxyhydroxides, as their terminal electron acceptor and produce ferrous iron (Weber et al. 2006). During sulfate reduction, microbes use sulfate as their terminal electron acceptor and produce sulfide (Widdel 1988).

Interactions between microorganisms that catalyze iron and sulfate reduction are variable. Competition between microbes for electron donors may confine the reactions to discrete zones in some settings (Chapelle and Lovley 1992). However, simultaneous occurrence of each reaction can benefit the microorganisms involved, potentially leading to development of mixed zones. Where both reactions are occurring, the ferrous iron and sulfide that are generated can precipitate from solution, thereby limiting the inhibitory effect of product accumulation (Bethke et al. 2008; Bethke et al. 2011). Lastly, some microorganisms have the ability to use iron as well as sulfur compounds in their metabolic reactions. This flexibility can allow microorganisms to drive iron reduction by participating in sulfur cycling where direct microbial reduction of iron is inhibited (Flynn et al. 2014). It may also allow some microorganisms to switch their metabolism between iron reduction and sulfate reduction, depending on conditions (Lovley et al. 1993).

Using thermodynamic calculations, previous studies have demonstrated that $\mathrm{pH}$ has the potential to influence interactions between microbial iron and sulfate reduction. Because the free energy yield of each metabolic reaction varies unequally with $\mathrm{pH}$, changes in $\mathrm{pH}$ can alter which reaction is energetically favored (Bethke et al. 2011; Postma and Jakobsen 1996). Reduction of ferric iron in oxides and oxyhydroxides consumes several protons, as shown in the following 
example microbial reaction, which includes goethite $(\alpha-\mathrm{FeOOH})$ as the source of ferric iron and acetate as the electron donor:

$$
\mathrm{CH}_{3} \mathrm{COO}^{-}+8 \mathrm{FeOOH}(\mathrm{s})+15 \mathrm{H}^{+} \rightarrow 2 \mathrm{HCO}_{3}^{-}+8 \mathrm{Fe}^{2+}+12 \mathrm{H}_{2} \mathrm{O}
$$

As a result, the energy yield of the reaction increases rapidly as $\mathrm{pH}$ decreases. In contrast, few protons are consumed in reducing sulfate and oxidizing acetate:

$$
\mathrm{CH}_{3} \mathrm{COO}^{-}+\mathrm{SO}_{4}^{2-}+\mathrm{H}^{+} \rightarrow 2 \mathrm{HCO}_{3}^{-}+\mathrm{H}_{2} \mathrm{~S}(\mathrm{aq})
$$

One proton is consumed if the reaction is written in terms of dihydrogen sulfide $\left(\mathrm{H}_{2} \mathrm{~S}\right)$, as above, or none, if written in terms of bisulfide (HS-). The free energy yield of sulfate reduction, therefore, varies little with $\mathrm{pH}$.

Reaction free energy yields can influence the balance between iron and sulfate reduction by affecting competition between microorganisms. Microbes that conserve energy from more energetically favorable reactions have physiological advantages, including fast reactions and more biomass yield, over those using less favorable reactions (Jin 2012; Jin and Bethke 2007; Lovley and Goodwin 1988; Roden and Jin 2011). Hence, the increasing free energy yield of iron reduction with decreasing $\mathrm{pH}$ may allow microbes capable of iron reduction to better compete with sulfate reducers in acidic environments than in alkaline environments (Bethke et al. 2011).

Results from a recent laboratory study are consistent with this conceptual model (Kirk et al. 2013). In bioreactors with elevated $\mathrm{CO}_{2}$ abundance ( $\left.1 \mathrm{~atm}\right)$ and acidic $\mathrm{pH}(5.9)$, microbial iron reduction accounted for virtually all of the respiration activity. In contrast, in identical 
bioreactors with lower $\mathrm{CO}_{2}$ abundance $(\sim 0.2 \mathrm{~atm})$ and alkaline $\mathrm{pH}(7.2)$, microbial iron reduction occurred but sulfate reduction actually consumed most of the electron donor.

Collectively, the results of these theoretical and laboratory analyses provide compelling evidence that $\mathrm{pH}$ can influence interactions between microbial iron and sulfate reduction. However, this relationship remains to be tested on a broad-scale in natural systems. The objective of this study is to use data from the U.S. Geological Survey (USGS) National Water Information System (NWIS) database to examine whether trends in geochemistry are consistent with $\mathrm{pH}$ as a control on a broad scale in natural aquifers. Specifically, we examine trends in products of iron and sulfate reduction individually as well as the concentration ratio of iron to sulfide $\left(\mathrm{Fe} / \mathrm{H}_{2} \mathrm{~S}\right)$ in groundwater, which has been shown to be useful as an indicator of the significance of iron reduction relative to sulfate reduction (Chapelle et al. 2009).

Our analysis includes data gathered from the 19 principal aquifer systems selected by the USGS for regional assessment (Lapham et al. 2005). Water from these aquifers provides approximately $75 \%$ of the groundwater used as drinking water in the U.S., underscoring the need to understand fundamental controls on water quality within them.

\section{Methods}

\section{Data Processing}

The NWIS water quality database contains data from 395,534 sites, at the time of this study. We isolated data from the database by searching for samples that were collected from wells (site type) and analyzed for sulfate (USGS parameter 00945). We completed this search individually for all 19 of the principal aquifer systems selected for regional assessment. 
In our analysis, we assume that dissolved iron (USGS parameter 01046) exists as ferrous iron $\left(\mathrm{Fe}^{2+}\right)$. Ferric iron $\left(\mathrm{Fe}^{3+}\right)$ is relatively insoluble at the near-neutral $\mathrm{pH}$ values of the samples in our datasets, implying that any dissolved iron in the samples is ferrous iron. Secondly, we assume that acid neutralization capacity (ANC) can substitute for alkalinity where alkalinity values are unavailable. Unlike alkalinity, ANC is measured on unfiltered samples. As such, ANC takes into account the neutralization capacity of solutes as well as particulates. For water that contains few particulates, ANC is virtually identical to alkalinity (Rounds 2012). Other than alkalinity, we gathered all other parameters in our analysis from single parameter codes.

After obtaining raw datasets for each system, we removed samples with chemistry inconsistent with iron and/or sulfate-reducing environments based on criteria defined by McMahon and Chapelle (2008). We eliminated (1) samples that contained $0.5 \mathrm{mg} \mathrm{L}^{-1}$ or more dissolved oxygen and/or nitrate and (2) samples that contained less than $0.5 \mathrm{mg} \mathrm{L}^{-1}$ sulfate. To limit uncertainty in our analysis, we removed samples that did not have reported values for oxygen, nitrate, or sulfate concentration. Lastly, we eliminated samples if they did not have a pH value measured during sample collection.

\section{Speciation and Solubility Modeling}

We used The Geochemists Workbench ${ }^{\circledR}$ software, version 10.0.3 (Aqueous Solutions), and the LLNL (Lawrence Livermore National Laboratory) thermodynamic database (Delany and Lundeen 1990) to evaluate aqueous speciation and mineral saturation indices. The software calculated activities using an extended form of the Debye-Hückel equation, the $B$-dot equation (Helgeson 1969), which is appropriate for solutions with low ionic strength ( $<0.5$ molal). The average ionic strength of samples in our datasets was 0.01 molal. We constrained the calculations 
with reported temperatures, major ion chemistry, and relevant data for minor chemical constituents (e.g., sulfide).

We considered mackinawite and siderite in our saturation index calculations. We only included samples in those calculations if each ion in the mineral precipitation reactions had concentrations reported to be above the detection limit. Siderite is present in the LLNL dataset. We added data from Benning et al. (2000) to the dataset for mackinawite solubility.

\section{Statistical Analysis}

To evaluate whether trends in the data are consistent with our hypothesis, we tested the extent to which $\mathrm{pH}$ correlated with other variables using Spearman's rho rank correlation tests, a non-parametric measure of the statistical dependence between two variables. We carried out statistical calculations using Prism GraphPad, version 6.00 (GraphPad Software). We used twotailed tests and considered $P$-values $<0.05$ to be significant. We substituted detection limit values for parameters found to be below detection, unless otherwise noted. Following previous researchers (Chapelle et al. 2013), we did not analyze the significance of correlations for parameters in individual datasets if those parameters were represented by less than 20 samples. This threshold was chosen to help limit error from random samples. However, we did include the data for all samples when statistically analyzing the datasets collectively.

\section{Results}

Table 1 lists the principal aquifers and the number of samples in each aquifer dataset before and after data filtering. The proportion of samples in each raw dataset that had reported concentrations for oxygen, nitrate, and sulfate averaged $22 \%$. Of those, the proportion with 
chemistry consistent with iron- and/or sulfate-reducing conditions averaged $18 \%$. Following sample filtering, only one dataset contained no samples (Hawaiian volcanic rock aquifer). Of the remainder, three datasets contained less than 20 samples and were therefore excluded from statistical analysis within the individual datasets.

Our analysis of these datasets focuses on chemical parameters relevant to microbial iron and sulfate reduction, including $\mathrm{pH}$, alkalinity, ferrous iron, sulfate, and sulfide. Table 2 and Figure 1 summarize geochemistry and the results of statistical analyses for the principal aquifers overall. A summary for individual principal aquifer datasets is available online (Table S1). Overall, $\mathrm{pH}$ values in our datasets average 6.85 , with $90 \%$ of the $\mathrm{pH}$ values falling between 4.9 and 8.3. The North Atlantic coastal plain aquifer dataset has the lowest average $\mathrm{pH}$ (6.03) and the New York and New England crystalline-rock aquifer dataset has the highest (8.06). 


\begin{tabular}{|c|c|c|c|}
\hline Aquifer system & $\begin{array}{c}\text { Raw } \\
\mathrm{n}^{1}\end{array}$ & $\begin{array}{c}\text { Full } \\
\mathrm{n}^{2}\end{array}$ & $\begin{array}{c}\mathrm{Fe}- \\
\mathrm{SO}_{4}^{2-} \\
\mathrm{n}^{3}\end{array}$ \\
\hline Basin and Range & 16587 & 2433 & 149 \\
\hline Biscayne & 1394 & 12 & 2 \\
\hline CA coastal basins & 16381 & 1799 & 366 \\
\hline Cambrian-Ord. & 4304 & 332 & 159 \\
\hline Central Valley & 9609 & 2393 & 358 \\
\hline Coastal lowlands & 10985 & 471 & 95 \\
\hline Columbia Plateau & 643 & 459 & 16 \\
\hline Denver Basin & 603 & 154 & 45 \\
\hline Edwards-Trinity & 5904 & 698 & 29 \\
\hline Floridian & 12125 & 1026 & 277 \\
\hline Glacial & 35369 & 6589 & 1492 \\
\hline Hawaiian & 378 & 51 & 0 \\
\hline $\begin{array}{l}\text { High Plains } \\
\text { MS embayment- }\end{array}$ & 5125 & 851 & 64 \\
\hline $\begin{array}{l}\text { TX coastal upland } \\
\text { North Atlantic }\end{array}$ & 8038 & 463 & 171 \\
\hline coastal plain & 35056 & 10647 & 1942 \\
\hline $\begin{array}{l}\text { NY-New England } \\
\text { Piedmont-Blue }\end{array}$ & 822 & 160 & 61 \\
\hline Ridge & 5227 & 1780 & 124 \\
\hline Snake River Plain & 597 & 396 & 4 \\
\hline Surficial & 3073 & 1039 & 187 \\
\hline \multicolumn{4}{|c|}{$\begin{array}{l}{ }^{1} \text { Number of samples extracted initially. } \\
{ }^{2} \text { Number of samples analyzed for dissolved } \\
\text { oxygen, nitrate, and sulfate. } \\
{ }^{3} \text { Number of samples with redox chemistry } \\
\text { consistent with iron- and/or sulfate-reducing } \\
\text { conditions. }\end{array}$} \\
\hline
\end{tabular}




\begin{tabular}{|c|c|c|c|c|c|c|}
\hline & unit & $\mathrm{n}^{1}$ & mean & $\mathrm{sd}^{2}$ & $\mathrm{r}^{3}$ & $P$ \\
\hline $\mathrm{pH}$ & & 5490 & 6.85 & 1.05 & & \\
\hline $\mathrm{Fe}^{2+}$ & $\mu \mathrm{M}$ & 4287 & 62.35 & 254.50 & -0.61 & $<0.0001$ \\
\hline $\mathrm{H}_{2} \mathrm{~S}$ & $\mu \mathrm{M}$ & 184 & 4.24 & 11.46 & -0.07 & 0.3405 \\
\hline $\mathrm{SO}_{4}{ }^{2-}$ & $\mathrm{mM}$ & 5490 & 1.14 & 7.27 & 0.21 & $<0.0001$ \\
\hline Alkalinity & meq $\mathrm{L}^{-1}$ & 4744 & 3.2 & 3.10 & 0.57 & $<0.0001$ \\
\hline $\mathrm{Fe}^{2+} / \mathrm{H}_{2} \mathrm{~S}$ & molar ratio & 129 & 161.9 & 786.5 & -0.43 & $<0.0001$ \\
\hline Siderite & $\log \mathrm{Q} / \mathrm{K}$ & 3537 & -0.72 & 1.07 & 0.23 & $<0.0001$ \\
\hline Mackinawite & $\log \mathrm{Q} / \mathrm{K}$ & 129 & -0.93 & 1.13 & 0.24 & 0.0065 \\
\hline$\Delta \mathrm{G}_{\mathrm{A}}$ FeR-SR & $\mathrm{kJ}(\mathrm{mol} \mathrm{e}-)^{-1}$ & 126 & 5.14 & 5.87 & -0.69 & $<0.0001$ \\
\hline \multicolumn{7}{|c|}{${ }^{1}$ Number of samples (n) } \\
\hline \multicolumn{7}{|c|}{${ }^{2}$ Standard deviation $(\mathrm{sd})$} \\
\hline
\end{tabular}

When the datasets are analyzed collectively, $\mathrm{pH}$ shares a significant negative correlation with iron concentration and a significant positive correlation with alkalinity and sulfate concentration. When each principal aquifer dataset is analyzed individually, the correlation between $\mathrm{pH}$ and iron is nearly uniform. Iron concentration shares a significant negative correlation with $\mathrm{pH}$ in 15 of 16 datasets. By comparison, the trend with $\mathrm{pH}$ of alkalinity and sulfate is less consistent between datasets. Of the 16 datasets with sufficient data, alkalinity significantly correlates with $\mathrm{pH}$ in ten: five positive correlations and five negative. Sulfate shares a significant positive correlation in one of 16 datasets and a significant negative correlation in five.

Unlike the parameters described above, $\mathrm{pH}$ does not significantly correlate with sulfide concentration in the datasets as a whole. However, differences in mean sulfide concentrations between samples with above and below average $\mathrm{pH}$ are considerable. For samples with above average $\mathrm{pH}$, mean sulfide content $(4.6 \mu \mathrm{M})$ is over 3 -fold greater than the mean sulfide content 
of samples with below average $\mathrm{pH}(1.4 \mu \mathrm{M})$. Only three datasets have a sufficient number of samples for individual statistical analysis. In those datasets, $\mathrm{pH}$ and sulfide do not significantly correlate.

\section{Discussion}

\section{Trends in Iron and Sulfide}

Variation in the balance between microbial iron reduction and sulfate reduction would affect concentrations of ferrous iron and sulfide. Ferrous iron is relatively soluble and may increase in concentration in response to microbial iron reduction (Chapelle and Lovley 1992). Similarly, sulfide concentration can increase in response to microbial sulfate reduction. Where both ferrous iron and sulfide coexist, they can precipitate as an iron-sulfide mineral (Benning et al. 2000):

$$
F e^{2+}+H_{2} S(a q) \rightarrow F e S(s)+2 H^{+}
$$

The extent to which ferrous iron or sulfide can accumulate in solution, therefore, depends on the extent to which one reaction is dominant over the other. If ferrous iron production by iron reduction exceeds sulfide production by sulfate reduction, iron can accumulate in solution while sulfide is held to low levels by precipitation. Conversely, sulfide would accumulate while ferrous iron is held to low levels if the opposite were true. These relationships imply that $\mathrm{pH}$ would tend to negatively correlate with ferrous iron concentration and positively correlate with sulfide concentration if decreasing $\mathrm{pH}$ favors iron reduction over sulfate reduction. 
Overall, trends in ferrous iron and sulfide concentration are consistent with the prediction. The negative correlation between iron and $\mathrm{pH}$ is one of the strongest we identified. Statistically significant correlations between sulfide concentrations and $\mathrm{pH}$ are absent in our datasets. However, differences in mean sulfide concentrations between samples with above and below average $\mathrm{pH}$ match the expected trend. Variation in aqueous iron and sulfide concentration in the datasets, therefore, provide broad-scale empirical support for an increase in the extent of iron reduction relative to sulfate reduction with decreasing $\mathrm{pH}$.

The ratio of iron to sulfide in the samples $\left(\mathrm{Fe} / \mathrm{H}_{2} \mathrm{~S}\right)$ provides a complementary test of these relationships. As iron reduction increases in significance relative to sulfate reduction, $\mathrm{Fe} / \mathrm{H}_{2} \mathrm{~S}$ ratios grow larger, making the ratio an indicator of the balance between each reaction (Chapelle et al. 2009). We calculated $\mathrm{Fe} / \mathrm{H}_{2} \mathrm{~S}$ ratios for samples with reported concentrations of both iron and sulfide. The results show that $\mathrm{Fe} / \mathrm{H}_{2} \mathrm{~S}$ ratios tend to increase with decreasing $\mathrm{pH}$ (Fig. 2), implying that the extent of iron reduction relative to sulfate reduction increases as $\mathrm{pH}$ decreases. Correlations between $\mathrm{pH}$ and $\mathrm{Fe} / \mathrm{H}_{2} \mathrm{~S}$ ratios are significant overall, providing additional evidence that the balance between the reactions varies with $\mathrm{pH}$ (Table 2).

According to Chapelle et al. (2009), $\mathrm{Fe} / \mathrm{H}_{2} \mathrm{~S}$ molar ratio values greater than 16 indicate that iron reduction is predominant, values less than 0.5 indicate sulfate reduction is predominant, and values between 16 and 0.5 can occur in mixed zones or in response to mixing of water between zones. Interpreted within this context, $18 \%$ of the ratios we calculated are consistent with predominantly sulfate-reducing conditions, $39 \%$ indicate mixed conditions, and $43 \%$ indicate predominantly iron-reducing conditions (Fig. 2). Samples with ratios consistent with predominantly iron-reducing conditions have an average $\mathrm{pH}$ of 7.10. In contrast, samples with 
ratios consistent with mixed and predominantly sulfate-reducing conditions have average $\mathrm{pH}$ values of 7.78 and 7.83 , respectively.

\section{Influence of Geochemical Reactions}

Trends in iron and sulfide concentration have likely been affected by precipitation of iron-sulfide minerals. Mackinawite $(\sim \mathrm{FeS})$ is typically the first iron-sulfide solid to form at low temperatures in iron-bearing, sulfate-reducing environments (Berner 1970; Michel et al. 2005). For samples with detectable iron and sulfide $(n=129)$, saturation index calculations demonstrate that $17 \%$ are saturated or supersaturated with respect to mackinawite (Fig. 3). Saturation index values share a significant positive correlation with $\mathrm{pH}$ overall in the principal aquifer datasets (Table 2). The tendency for higher sulfide concentrations in samples with above average $\mathrm{pH}$ may contribute to this trend. Variation in mackinawite solubility with $\mathrm{pH}$, however, likely also contributes. Mackinawite precipitation releases protons (reaction 3), indicating that it would be more favorable in alkaline environments than acidic environments.

Mackinawite precipitation may contribute to the lack of a statistically significant correlation between aqueous sulfide and $\mathrm{pH}$. By removing iron and sulfide from solution, mackinawite precipitation can partially conceal iron- and sulfate-reducing activity. Because of the stoichiometry of each reaction, however, it has a greater potential to conceal sulfate reduction (Park et al. 2006). Per eight electron transfer, iron reduction generates eight ferrous iron ions whereas sulfate reduction generates only a single sulfide (reactions 1 and 2). As a result, sulfide production will only outpace ferrous iron production if electron donor consumption by sulfate reduction exceeds that of iron reduction by at least a factor of eight. Even where the rate of 
sulfate reduction increases considerably with increasing $\mathrm{pH}$, therefore, sulfide concentration could be held to low levels by mackinawite precipitation.

In addition to mackinawite, trends in iron concentrations may have also been impacted by siderite $\left(\mathrm{FeCO}_{3}\right)$ precipitation (Fig. 3). In samples with sufficient data $(\mathrm{n}=3537)$, our calculations indicate that $26 \%$ were saturated or supersaturated with respect to siderite. Analyzed collectively, $\mathrm{pH}$ shares a significant positive correlation with the calculated saturation index of siderite (Table 2). This trend likely reflects the positive correlation between alkalinity and $\mathrm{pH}$ overall as well as variation in siderite solubility with $\mathrm{pH}$. When analyzed individually, the saturation index of siderite shares a significant positive correlation with $\mathrm{pH}$ in six of 15 datasets and a significant negative correlation in one. Hence, it is possible that siderite precipitation has masked to varying extents the trends between iron and $\mathrm{pH}$ in different principal aquifer datasets.

Lastly, trends in iron concentration have likely been affected by sorption reactions. The ability of ferrous iron to sorb onto oxide and oxyhydroxide surfaces increases with $\mathrm{pH}$. Dixit and Hering (2006), for example, found that sorption of ferrous iron onto goethite was minimal at $\mathrm{pH}$ 5 but increased to maximum levels at $\mathrm{pH} 7.5$. Variation with $\mathrm{pH}$ in the ability of ferrous iron to sorb, therefore, may have reinforced the negative correlations between iron and $\mathrm{pH}$ in the datasets.

This effect may be greatest in aquifers that have relatively low average $\mathrm{pH}$. In the North Atlantic coastal plain aquifer system dataset, for example, $18 \%$ of the samples had a $\mathrm{pH}$ less than 5.0, values at which ferrous iron sorption would be minimal, and $13 \%$ had a $\mathrm{pH}$ greater than 7.5 , values at which considerable sorption could occur. The ability of ferrous iron to sorb would vary sharply across the $\mathrm{pH}$ range of samples in that dataset. However, strong correlation between $\mathrm{pH}$ and ferrous iron also exists in datasets with relatively high average $\mathrm{pH}$. In the New York and 
New England crystalline-rock aquifer system dataset, for example, $81 \%$ of the samples had a $\mathrm{pH}$ greater than 7.5 , values above which the ability of iron to sorb may vary relatively little. Nonetheless, the correlation between $\mathrm{pH}$ and ferrous iron is stronger in that dataset than all but three of the other datasets. Within alkaline aquifer datasets, such as the New York and New England aquifer dataset, variation in the relative significance of iron reduction may be more important than variation in sorption as the driver for the correlation between iron and $\mathrm{pH}$.

\section{Bioenergetics}

We performed thermodynamic calculations to assess whether thermodynamic controls on microbial interactions may be a cause of the inferred changes in microbial activity. Our calculations evaluate energy available in the environment for iron reduction relative to sulfate reduction. For the calculations, we represent iron and sulfate reduction using reactions 1 and 2, respectively. Energy available in the environment $\left(\Delta G_{A}\right)$ for a microbial reaction is the negative of the free energy change of that reaction $\left(\Delta G_{r}\right)$, calculated according to:

$$
\Delta G_{A}=-\Delta G_{r}=-\left[\Delta G_{T}^{\circ}+R T \ln \prod_{i}\left(\gamma_{i} \times m_{i}\right)^{v_{i}}\right]
$$

where $\Delta G_{T}^{\circ}$ is the standard Gibbs free-energy change for reaction $r$ at temperature $T(\mathrm{~K}), R$ represents the gas constant $\left(\mathrm{J} \cdot \mathrm{mol}^{-1} \cdot \mathrm{K}^{-1}\right), \gamma_{i}$ and $m_{i}$ are the activity coefficient $\left(\mathrm{molal}^{-1}\right)$ and molality of the $i$ th chemical species in the reaction, and $v_{i}$ is the stoichiometric coefficient of that species, which is positive for products and negative for reactants. We used The Geochemists Workbench ${ }^{\circledR}$ software and the LLNL thermodynamic database to evaluate $\Delta G_{T}^{\circ}$ values for each sample. 
We calculated $\Delta G_{A}$ for every sample in our datasets with reported ferrous iron and sulfide concentrations. We then calculated the difference in energy available for each reaction in $\mathrm{kJ}$ per mole of electrons transferred by subtracting energy available for sulfate reduction from that available for iron reduction $\left(\Delta \mathrm{G}_{\mathrm{A}} \mathrm{FeR}-\mathrm{SR}\right)$.

Data constraining concentrations of electron donors such as acetate and dihydrogen $\left(\mathrm{H}_{2}\right)$ are nearly absent from our datasets. Nonetheless, our analysis is not impacted by uncertainty in electron donor concentration. If we assume that microbes catalyzing the reactions compete for the same electron donor, variation in the concentration of that electron donor would affect each reaction equally as long as the reactions are written with the same stoichiometric coefficient for the electron donor. Moreover, the identity of the electron donor also has a negligible influence because the calculation results are expressed in terms of the difference in available energy per electron transfer. A virtually identical result would be obtained, for example, if the calculation considered reactions with dihydrogen as the electron donor instead of acetate.

As $\mathrm{pH}$ decreases, differences in available energy increase, suggesting that iron reduction gains an increasing energy advantage over sulfate reduction (Fig. 4, Table 2). Across different $\mathrm{pH}$ values, the energy available for iron reduction is not always greater than that for sulfate reduction. Specifically, sulfate reduction is more favorable than iron reduction in $17 \%$ of the samples. These samples were collected from environments with high $\mathrm{pH}$ (avg. 8.56). In contrast, the average $\mathrm{pH}$ is 7.25 in samples from environments where iron reduction holds the advantage. These results are consistent with thermodynamic controls on microbial interactions as a mechanism for shifts in the balance between iron and sulfate reduction with $\mathrm{pH}$.

The increase in energy available for iron reduction relative to sulfate reduction results primarily from variation in $\mathrm{pH}$. Geochemical changes that would increase energy available for 
microbial iron reduction include a decrease in the abundance of reaction products (alkalinity and ferrous iron) and $\mathrm{pH}$, as noted previously. Changes that would increase energy available for microbial sulfate reduction include a decrease in alkalinity and sulfide content and an increase in sulfate concentration. Of these variables, $\mathrm{pH}$ has the largest potential to affect differences in the energy yield of each group because of the large stoichiometric coefficient for protons in the metabolic reaction for iron reduction (reaction 1). Indeed, in contrast to $\mathrm{pH}$, none of the other geochemical variables considered are significantly correlated with the differences in available energy we calculated (results not shown).

Sources of uncertainty in these calculations include (1) the identity of ferric iron minerals at each site and (2) errors associated with $\mathrm{pH}$ measurements. Our datasets do not constrain the form or abundance of ferric iron where samples were collected. Our calculations assume that goethite is available. Goethite is the most abundant ferric oxyhydroxide (Cornell and Schwertmann 2003), making it a reasonable choice. Numerous other ferric iron minerals could be present, however. Those that are less stable than goethite would yield more energy for iron reduction than our calculations predict and those that are more stable would yield less (Postma and Jakobsen 1996). Nonetheless, energy available for iron reduction would generally increase with decreasing $\mathrm{pH}$. Measurements of groundwater $\mathrm{pH}$ can be erroneously high as a result of carbon dioxide outgassing following sample collection (Macpherson 2009). Where this is the case, our calculation would underestimate energy available for iron reduction to some degree. Despite these sources of uncertainty, our calculations provide a useful constraint on how energy available for each reaction varies with $\mathrm{pH}$ in the principal aquifer systems.

\section{Implications}


The results of this study shed light on potential biogeochemical impacts of environmental change in groundwater systems. Widespread human activities that add acid to natural waters include agriculture, mining of coal and metal ores, and emissions from fossil fuel combustion and smelting of ores (Rice and Herman 2012). Where these acid loadings cause groundwater $\mathrm{pH}$ to decrease in anoxic zones of aquifers, our study indicates that microbial iron reduction will increase in significance relative to sulfate reduction. These ecological changes favor increases in iron concentration and decreases in sulfide production. By affecting abundances of iron oxides and sulfide minerals, these changes could in-turn impact the mobility of numerous trace elements (Huerta-Diaz and Morse 1992; Kirk et al. 2010). Our ability to anticipate and manage these potential impacts will be improved by understanding microbial processes and factors controlling groundwater $\mathrm{pH}$ within individual aquifer systems.

\section{Conclusions}

Previous theoretical and laboratory studies indicate that $\mathrm{pH}$ can influence interactions between microbial iron and sulfate reduction. Here we consider the environmental relevance of this relationship by examining broad-scale geochemical data from principal aquifer systems. Trends in dissolved iron and sulfide concentration in our aquifer datasets are consistent with an increase in the significance of iron reduction relative to sulfate reduction with decreasing $\mathrm{pH}$. Thermodynamic calculations show that shifts in the balance between each reaction may occur in response to variation in thermodynamic controls on microbial activity. The calculations indicate that iron reduction gains an increasing energy advantage over sulfate reduction with decreasing $\mathrm{pH}$. Our findings provide evidence that $\mathrm{pH}$ is a broad-scale control on interactions between microorganisms that catalyze iron and sulfate reduction. These findings imply that future 
environmental changes that alter the $\mathrm{pH}$ of groundwater in anoxic aquifers may affect water quality by causing changes in the balance between iron reduction and sulfate reduction.

\section{Supporting Information}

Additional Supporting Information may be found in the online version of this article:

Table S1: Summary of geochemical data and statistics for each individual aquifer system dataset.

\section{Acknowledgments}

The authors thank Dr. Janet Paper and three anonymous reviewers for thoughtful comments that improved this manuscript. This material is based upon work supported by the National Science Foundation under Awards EPS-0903806 and EAR-0819954 and support from the State of Kansas through the Kansas Board of Regents.

\section{References}

Benning, L. G., Wilkin, R. T., and Barnes, H. L. 2000. Reaction pathways in the Fe-S system below 100 degrees C. Chemical Geology 167, no. 1-2: 25-51.

Berner, R. A. 1970. Sedimentary pyrite formation. American Journal of Science 268, no. 1: 1-23.

Bethke, C. M., Ding, D., Jin, Q., and Sanford, R. A. 2008. Origin of microbiological zoning in groundwater flows. Geology 36, no. 9: 739-742.

Bethke, C. M., Sanford, R. A., Kirk, M. F., Jin, Q., and Flynn, T. M. 2011. The thermodynamic ladder in geomicrobiology. American Journal of Science 311, no. 3: 183-210. 
Böhlke, J. K. 2002. Groundwater recharge and agricultural contamination. Hydrogeology Journal 10, no. 1: 153-179.

Chapelle, F. H. 2001. Ground-Water Microbiology and Geochemistry, New York: John Wiley \& Sons.

Chapelle, F. H., Bradley, P. M., Journey, C. A., and McMahon, P. B. 2013. Assessing the relative bioavailability of DOC in regional groundwater systems. Ground Water 51, no. 3: 363-372.

Chapelle, F. H., Bradley, P. M., Thomas, M. A., and McMahon, P. B. 2009. Distinguishing ironreducing from sulfate-reducing conditions. Ground Water 47, no. 2: 300-305.

Chapelle, F. H., and Lovley, D. R. 1992. Competitive exclusion of sulfate reduction by Fe(III)reducing bacteria: A mechanism for producing discrete zones of high-iron ground water. Ground Water 30, no. 1: 29-36.

Cornell, R. M., and Schwertmann, U. 2003. The Iron Oxides, $2^{\text {nd }}$. New York: Wiley-VCH.

Delany, J. M., and Lundeen, S. R. 1990. The LLNL thermochemical database: Lawrence Livermore National Laboratory.

Dixit, S., and Hering, J. G. 2006. Sorption of Fe(II) and As(III) on goethite in single- and dualsorbate systems. Chemical Geology 228, no. 1-3: 6-15.

Flynn, T. M., O'Loughlin, E. J., Mishra, B., DiChristina, T. J., and Kemner, K. M. 2014. Sulfurmediated electron shuttling during bacterial iron reduction. Science 344, no. 6187: 10391042.

Flynn, T. M., Sanford, R. A., Ryu, H., Bethke, C. M., Levine, A. D., Ashbolt, N. J., and Santo Domingo, J. W. 2013. Functional microbial diversity explains groundwater chemistry in a pristine aquifer. BMC Microbiology 13, no. 146. 
Gerlach, R., and Cunningham, A. B. 2010. Influence of Biofilms on Porous Media Hydrodynamics. In Porous Media: Applications in Biological Systems and Biotechnology, ed. Vafai, K. New York: CFC Press.

Green, T. R., Taniguchi, M., Kooi, H., Gurdak, J. J., Allen, D. M., Hiscock, K. M., Treidel, H., and Aureli, A. 2011. Beneath the surface of global change: Impacts of climate change on groundwater. Journal of Hydrology 405, no. 3-4: 532-560.

Harvey, O. R., Qafoku, N. P., Cantrell, K. J., Lee, G., Amonette, J. E., and Brown, C. F. 2013. Geochemical implications of gas leakage associated with geological $\mathrm{CO}_{2}$ storage - a qualitative review. Environmental Science \& Technology 47, no. 1: 23-36.

Helgeson, H. C. 1969. Thermodynamics of hydrothermal systems at elevated temperatures and pressures. American Journal of Science 267, no. 7: 729-804.

Huerta-Diaz, M. A., and Morse, J. W. 1992. Pyritization of trace metals in anoxic marine sediments. Geochimica et Cosmochimica Acta 56, no. 7: 2681-2702.

Jin, Q. 2012. Energy conservation of anaerobic respiration. American Journal of Science 312, no. 6: 573-628.

Jin, Q., and Bethke, C. M. 2007. The thermodynamics and kinetics of microbial metabolism. American Journal of Science 307, no. 4: 643-677.

Kirk, M. F., Roden, E. E., Crossey, L. J., Brearley, A. J., and Spilde, M. N. 2010. Experimental analysis of arsenic precipitation during microbial sulfate and iron reduction in model aquifer sediment reactors. Geochimica et Cosmochimica Acta 74, no. 9: 2538-2555.

Kirk, M. F., Santillan, E. F. U., Sanford, R. A., and Altman, S. J. 2013. CO 2 -induced changes in microbial activity affect carbon trapping and water quality in anoxic bioreactors. Geochimica et Cosmochimica Acta 122 198-208. 
Lapham, W. W., Hamilton, P. A., and Myers, D. N. 2005. National Water-Quality Assessment Program - Cycle II - Regional Assements of Aquifers: U.S. Geological Survey, Fact Sheet 2005-3013.

Lovley, D. R., and Goodwin, S. 1988. Hydrogen concentrations as an indicator of the predominant terminal electron-accepting reactions in aquatic sediments. Geochimica et Cosmochimica Acta 52, no. 12: 2993-3003.

Lovley, D. R., Roden, E. E., Phillips, E. J. P., and Woodward, J. C. 1993. Enzymatic iron and uranium reduction by sulfate-reducing bacteria. Marine Geology 113, no. 1-2: 41-53.

Macpherson, G. L. 2009. $\mathrm{CO}_{2}$ distribution in groundwater and the impact of groundwater extraction on the global C cycle. Chemical Geology 264, no. 1-4: 328-336.

McMahon, P. B., and Chapelle, F. H. 2008. Redox processes and water quality of selected principal aquifer systems. Ground Water 46, no. 2: 259-271.

Michel, F. M., Antao, S. M., Chupas, P. J., Lee, P. L., Parise, J. B., and Schoonen, M. A. A. 2005. Short- to medium-range atomic order and crystallite size of the initial FeS precipitate from pair distribution function analysis. Chemistry of Materials 17, no. 25 : 6246-6255.

Park, J., Sanford, R. A., and Bethke, C. M. 2006. Geochemical and microbiological zonation of the Middendorf aquifer, South Carolina. Chemical Geology 230, no. 1-2: 88-104.

Postma, D., and Jakobsen, R. 1996. Redox zonation: Equilibrium constraints on the $\mathrm{Fe}(\mathrm{III}) / \mathrm{SO}_{4}-$ reduction interface. Geochimica et Cosmochimica Acta 60, no. 17: 3169-3175.

Rice, K. C., and Herman, J. S. 2012. Acidification of Earth: An assessment across mechanisms and scales. Applied Geochemistry 27, no. 1: 1-14. 
Roden, E. E., and Jin, Q. 2011. Thermodynamics of microbial growth coupled to metabolism of glucose, ethanol, short-chain organic acids, and hydrogen. Applied and Environmental Microbiology 77, no. 5: 1907-1909.

Rounds, S. 2012. Alkalinity and acid neutralizing capacity. In U.S. Geological Survey Techniques of Water-Resource Investigations, Book 9, Chapter A6, Section 6.6, ed. Wilde, F., U.S. Geological Survey.

Warner, N. R., Jackson, R. B., Darrah, T. H., Osborn, S. G., Down, A., Zhao, K. G., White, A., and Vengosh, A. 2012. Geochemical evidence for possible natural migration of Marcellus Formation brine to shallow aquifers in Pennsylvania. Proceedings of the National Academy of Sciences of the United States of America 109, no. 30: 11961-11966.

Weber, K. A., Achenbach, L. A., and Coates, J. D. 2006. Microorganisms pumping iron: anaerobic microbial iron oxidation and reduction. Nature Reviews Microbiology 4, no. 10: $752-764$.

Widdel, F. 1988. Microbiology and ecology of sulfate- and sulfur-reducing bacteria. In Biology of Anaerobic Microorganisms, ed. Zehnder, A. J. B. New York: John Wiley \& Sons.

\section{Figure captions}

Figure 1. Variation with $\mathrm{pH}$ in the (A) alkalinity, (B) iron, (C) sulfate, and (D) sulfide content of groundwater samples. Data points are color-coded by the average $\mathrm{pH}$ of samples for each principal aquifer dataset. The group with average $\mathrm{pH}$ less than 7 includes the Coastal lowlands, Northern Atlantic coastal plain, and surficial aquifer system datasets. The group with average $\mathrm{pH}$ from 7 to 7.49 includes the Biscayne, Edwards-Trinity, Mississippi embayment-Texas coastal uplands, glacial, Piedmont and Blue Ridge crystalline-rock and carbonate-rock, and Cambrian- 
Ordovician, Central Valley, and Floridian aquifer system datasets. The group with average $\mathrm{pH}$ from 7.5 to 7.99 include the High Plains, Snake River Plain basin-fill and basaltic-rock, California coastal basins, Basin and Range basin fill and carbonate-rock, and Columbia Plateau basin-fill and basaltic-rock aquifer system datasets. Lastly, the group with average $\mathrm{pH}$ at 8 or above includes Denver Basin and New York and New England crystalline-rock aquifer system datasets.

Figure 2. Variation with $\mathrm{pH}$ in the molar ratio of iron to sulfide in groundwater. Ratios indicative of zones dominated by iron reduction (Fe red'n), mixed zones, and zones dominated by sulfate reduction $\left(\mathrm{SO}_{4}{ }^{2-}\right.$ red'n) are defined according to Chapelle et al. (2009). See Figure 1 for an explanation of symbol colors.

Figure 3. Variation with $\mathrm{pH}$ in the saturation index of (A) mackinawite and (B) siderite. See Figure 1 for an explanation of symbol colors.

Figure 4. Variation with $\mathrm{pH}$ in free energy available for iron reduction relative to sulfate reduction $\left(\Delta \mathrm{G}_{\mathrm{A}} \mathrm{FeR}-\mathrm{SR}\right)$. Positive values indicate that iron reduction is more energetically favorable than sulfate reduction. See Figure 1 for an explanation of symbol colors. 